\title{
Reproductive health services utilization and its associated factors among adolescents in Debre Berhan town, Central Ethiopia: a community-based cross-sectional study
}

Kenean Getaneh Tlaye ${ }^{1 *}$, Mesfin Abebe Belete ${ }^{2}$, Tefera Mulugeta Demelew², Mikiyas Amare Getu and Feleke Hailemichael Astawesegn ${ }^{3}$

\begin{abstract}
Background: Utilization of reproductive health services is an important component in preventing adolescents from different sexual and reproductive health problems. As a result, the extent of their service utilization should be determined before implementing any kind of interventions. Therefore, this study was aimed at assessing the level of reproductive health services utilization and its associated factors among adolescents who live in Debre Berhan town.

Methods: A community-based cross-sectional method was employed in this study from April 5-May 1, 2016. A multistage systematic sampling technique was applied to select a total of 648 adolescents living in 5 randomly selected kebeles of Debre Berhan town. Moreover, a logistic regression was done to identify independent predictors of reproductive health service utilization.

Results: Accordingly, the major findings of this study reveals that about one-third (33.8\%) of adolescents utilized at least one of reproductive health services. Adolescents who had discussed sexual and reproductive health issues with their sexual partner and peers were two times more likely to use reproductive health services than their counter parts $(\mathrm{AOR}=2.368,95 \% \mathrm{Cl}: 1.168-4.802$ and $\mathrm{AOR}=2.360,95 \% \mathrm{Cl}: 1.155-4.820$ respectively). Adolescents who weren't coresided with both their parents were also about two times more likely to utilize reproductive health service than those who were living together $(A O R=2.570,95 \% \mathrm{Cl}=1.155-4.820)$. Positive perception of oneself towards acquisition of Human Immunodeficiency Virus urged the adolescents to use RH services twice than those who didn't perceive themselves as risky ( $\mathrm{AOR}=2.231,95 \% \mathrm{Cl}: 1.001-4.975)$.

Conclusion: Succinctly speaking, the analysis of the major finding suggests that the utilization of reproductive health services among adolescents in the study area was low. Discussion with sexual partner and peers, risk perception of oneself towards the acquisition of human immune-deficiency virus was among the predictors of reproductive health services usage.
\end{abstract}

Keywords: Reproductive health, Adolescents, Service utilization

\footnotetext{
* Correspondence: kenyget24@hotmail.com

${ }^{1}$ Nursing Department, Health Science Faculty, Woldia University, Woldia,

Ethiopia

Full list of author information is available at the end of the article
}

(C) The Author(s). 2018 Open Access This article is distributed under the terms of the Creative Commons Attribution 4.0 International License (http://creativecommons.org/licenses/by/4.0/), which permits unrestricted use, distribution, and reproduction in any medium, provided you give appropriate credit to the original author(s) and the source, provide a link to the Creative Commons license, and indicate if changes were made. The Creative Commons Public Domain Dedication waiver (http://creativecommons.org/publicdomain/zero/1.0/) applies to the data made available in this article, unless otherwise stated. 


\section{Plain English summary}

Reproductive Health Service includes access to information and services on prevention, diagnosis, counseling, treatment and care, and requires that all people can safely reach services without travelling a long distance or wasting time. This means services and treatments must be affordable to people based on the principle of equity. The rationale behind the study was to investigate the level of reproductive health services utilization and to find out the associated factors among adolescents in order to provide evidence-based information and recommendations to alter possible future interventions.

A community based cross-sectional study design was conducted on selected adolescents from 5 'kebeles' of Debre Berhan town. In doing so, Adolescents who have sought or received at least one service out of the four identified RH services under the study, that is, Sexual and Reproductive Health (SRH) information and education service; modern contraceptive service; Voluntary Counseling and Testing for HIV (VCT) service; and Sexually Transmitted Infections (STI) diagnosis and treatment service utilization were considered to be used by the adolescents.

Six hundred forty-eight participants responded to the questionnaires yielded a response rate of $95 \%$. The mean age of the respondents was 17.13 (SD + 1.33). Respondents who had good knowledge were 356 (54.9\%), and $68.5 \%$ of all adolescents had high geographical accessibility to reproductive health service. Adolescents who had discussed sexual and reproductive health issues with their sexual partner and peers, adolescents who didn't resided with both their parents and positive perception of oneself towards acquisition of HIV/AIDS urged adolescents to use those services.

In conclusion; despite the major proportion of adolescents having good knowledge and high geographical accessibility to reproductive health services, the use of $\mathrm{RH}$ services in the study area was low.

\section{Background}

According to World Health Organization (WHO), adolescents are people between 10 and 19 years of age; they make $20 \%$ of the world's population, of whom $85 \%$ live in developing countries. Adolescence is characterized by significant physiological, psychological, and social changes that put them on high risk of sexual and reproductive health related problems. This is because adolescents were considered to be relatively healthy, citizens who lives without a heavy "burden of disease" [1, 2].

Reproductive health care is defined as the constellation of methods, techniques, and services that contribute to reproductive health and well-being by preventing and solving sexual health problems [3].
The WHO stated that about one half of all HIV infections worldwide occur among people aged 25 years and under 25 years of age. In addition, up to 100 million youths become infected with curable sexually transmitted diseases. Every year an estimated of 1.7 million youths lose their life prematurely due to preventable or treatable problems such as accidents, violence, pregnancy related complications, and other illnesses. For instance, in Africa, it was estimated that $60 \%$ of all new HIV infections occur among the youth aged $15-19$ years [2]. Sub-Saharan Africa remains the most affected region in the world with an estimate of 22.5 million people living with HIV and approximately 1.7 million new infections occurred in the region. Furthermore, premarital sexual activity has the highest rate in Sub-Saharan Africa, where more than half of girls aged 15-19 have sexual experience [4].

According to the Ethiopian Demographic and Health Survey (EDHS) of 2011, among the age group of 15-24 years, HIV prevalence was $0.4 \%$. That is, the utilization of family planning services in the existing health care system by young people was also very low. As a result, there is a high rate of unwanted pregnancies which often result in abortions and its complications. From all posts, among incomplete abortion treatment seekers, the majority $(67.2 \%)$ of them were under 24 years of age. In addition, the 2011 EDHS figured out that contraceptive use among adolescents were lower when compared with other age groups [5].

The concern about adolescent sexual and reproductive health has grown due to unprecedented increasing rates of sexual activity, early pregnancies and sexually transmitted infections including human immune deficiency virus among adolescents $[6,7]$, which in turn negatively affect their health, productivity, and quality of life.

As a result, the Federal Ministry of Health (FMOH) launched several strategies to promote adolescents and youth reproductive health services such as the National Reproductive Health Strategy implemented during 2006-2015, and National Adolescent and Youth Reproductive Health Strategy implemented during 2007-2015. Similarly, Standards on Youth Friendly Reproductive Health Services; and also tools for planning, implementation, and monitoring at different levels of the health system were prepared. What is more, youth friendly health services were established so as to provide $\mathrm{RH}$ services to adolescents and youths in line with the existing health facilities. In spite of all the above facts, Ethiopia still has huge gap in accessing adolescents and youth with reproductive health services [8].

The evidences discussed above imply that adolescents' health problems were related to their utilization of $\mathrm{RH}$ service either directly or indirectly because it is obvious that the more readily the services are utilized, the less 
the problems will be. Even though certain factors were recognized as reasons for the low-level $\mathrm{RH}$ service utilization so far, additional in-depth investigation is needed especially at areas where no prior studies have been conducted. Therefore, the rationale behind this research was to investigate the level of reproductive health services utilization and to find out associated factors among adolescents who live in Debre Berhan town, in order to provide evidence-based information and recommendations for possible future interventions. It also generates relevant information that could help to design appropriate $\mathrm{RH}$ programs for adolescents.

\section{Methods}

\section{Study area and period}

Cross-sectional study was conducted from April 5-May 1, 2016 in Debre Berhan town, North Shoa, Ethiopia with an objective to assess the reproductive health service utilization and to find out associated factors among adolescents of age 15-19 years. Debre Berhan town is located at $9^{\circ} 41^{\prime} \mathrm{N} 39^{\circ} 32^{\prime} \mathrm{E} / 9.683^{\circ} \mathrm{N} 39.533^{\circ} \mathrm{E}$, that is, 130 $\mathrm{km}$ North of Addis Ababa, the capital city of Ethiopia. It has $2840 \mathrm{~m}$ elevation above sea level and covers $14.71 \mathrm{~km}^{2}$. The town is founded by Emperor Zara Yakob in 1456 [9], and it has 9 administrative kebeles. According to the information obtained from the District Health Office, in $2015 / 16$ population data, the total population size of the district was 92,887 , out of which 50,883 $(54.78 \%)$ were females. The number of households and adolescents (10-19 years of age) in the district were estimated to be 18,453 and 22,014 respectively. In the town, there were 2 hospitals, 3 health centers, 9 health posts, 6 private clinics, and 17 pharmacies which render health services for the community. Family planning service was also available in most of the above health institutions including health posts.

\section{Population and sampling Source of population}

The source population was all households of 5 selected kebeles of Debre Berhan town that hosts adolescents of age 15-19.

\section{Study population}

Adolescents of age 15-19 who were living in the selected household from 5 selected kebeles of Debre Berhan town.

\section{Sample size and sampling procedure Sample size calculation}

The actual sample size was determined considering the following assumptions: level of confidence was taken to be $95 \%$ with $\alpha=0.05$ value (which yields $Z \alpha / 2=1.96$ on the standard normal distribution curve), a $5 \%$ margin of error $(\mathrm{d}=0.05)$ and a proportion of $72.2 \%$ voluntary counseling and testing (VCT) service utilization obtained from previous study conducted in Gondar town (in northern Ethiopia) among adolescents age 15-19 (12). Based on this assumption, the actual sample size for the study was computed using single population proportion formula as indicated below.

$$
n=\frac{\left(Z \frac{a}{2}\right)^{2} p(1-p)}{d^{2}}
$$

Where, $\mathrm{n}=$ Sample size.

$\mathrm{z}=$ the value of the standard normal curve score corresponding to the given confidence interval $=1.96$.

$\mathrm{p}=$ Prevalence rate of $\mathrm{RH}$ service utilization $=0.72$.

$\mathrm{d}=$ the permissible margin of error (the required precision) $=5 \%$

$$
\frac{(1.96)^{2} \times 0.72(1-0.72)}{(0.05)^{2}}=309.8
$$

Considering Design effect of 2 and 10\% non- response rate: the total sample size was

$$
309.8 \times 2+62=682
$$

\section{Sampling procedure}

A multi-stage sampling technique was employed for the selection of the sampling units. In the district, there were 9 kebeles, of which a total of 5 kebeles were selected using lottery method. The sample size for each selected kebeles was determined proportionally to the number of households within each kebele. Then, systematic sampling method was employed to select the households where adolescents reside from each kebele assuming in a household at least one adolescent aged 15-19 will be found. In cases of household with more than one eligible respondent, only one respondent was selected by using a lottery method.

\section{Data collection tools and procedure}

A self-administered, semi-structured questionnaire was used in the study. The questionnaire was developed by combining the John Cleland's Illustrative questionnaire for interview-survey with young people's [10], and also several literatures reviewed to achieve the research objectives.

The main points included in the questionnaire were: socio demographic characteristics; adolescents' individual attribute regarding to sexuality and reproductive health; service accessibility (geographical accessibility); and four main aspects of RH services (sexual and RH information and education, modern contraceptive, voluntary counseling and testing for HIV, STI diagnosis and treatment) (See Additional file 1). The data was collected 
by 6 trained data collectors for 25 days under close supervision and facilitation by 1 supervisor and the principal investigator as needed.

\section{Data quality assurance}

The questionnaire and consent documents were first developed in English language, and then translated into Amharic language for data collection purpose using the local language. Then finally, the subject matter experts retranslated the data back into English language in collaboration with a translation expert to check its consistency.

Face validity of the questionnaire was assessed. Items interpretability and understandability by the study participants was evaluated by pre-testing the questionnaire on 34 adolescents (5\% of the total sample size) living in unselected kebeles, and the necessary correction has been taken accordingly. Six data collectors (3 females and 3 males) who were third year Nursing Department students from Debre Berhan University participated in the data collection process of the study after they were provided with the appropriate orientation and guidance about the overall project plan, and how to approach and communicate with adolescents to elicit reliable data.

The anticipated time duration to complete the questionnaire was not more than $30 \mathrm{~min}$. For respondents who were absent in the first visit, a maximum of two additional schedules were established for revisit. Supervision was also done on the spot by principal investigator and supervisor. The collected data was checked for its completeness and clarity by the principal investigator daily. Data cleaning and cross-checking were also done before analysis.

\section{Data processing and analysis}

After checking for its completeness, the data was processed and analyzed by SPSS version 21. Descriptive and analytical statistics including, bivariate and multivariate analysis was employed. Percentage, ratios, frequency distribution, measure of central tendency, and measure of dispersion have been used for describing different variables. Bivariate analysis has been used to examine association between dependent and independent variables. All variables with $p<0.05$ in bivariate analysis was fitted in to the multiple variable logistic regression model to identify factors associated with $\mathrm{RH}$ service utilization. $P$ value less than 0.05 was considered as a level of significance.

\section{Terms and operational definition}

Adolescent

In this study adolescent stands for boys and girls between the ages of 15-19.

\section{Discussion on SRH issues}

Adolescents who discussed at least two SRH issues (Condom, STI/HIV/AIDS, abstinence, unwanted pregnancy, contraception) with health care provider in the last 12 months. The same was applied with peer, and sexual partner.

\section{History of sexual exposure}

Adolescents who ever experience sex in their life were classified as having the history of sexual exposure and not otherwise.

\section{Knowledge about reproductive health service}

Adolescents who score above the mean of reproductive health service related questions were labeled as having high knowledge and those score below the mean were considered as having low knowledge. The questions were about the available types of services and types of service delivery points (providers) within the area, which included a total of eight types of services and seven service delivery points.

\section{Media exposure on SRH issues}

Adolescents who were exposed to mass media (including radio, television, magazine/newspaper and pamphlet) on at least two SRH issues (Condom, STI/HIV/AIDS, abstinence, unwanted pregnancy, contraception) in the past 12 months.

\section{Modern contraceptive service utilization}

Adolescents who used any of the modern birth controlling methods (contraceptives) in the past 12 months.

\section{Perception of risk towards HIV/AIDS}

Adolescent's attitude towards perceiving themselves as susceptible to HIV infection.

\section{$R H$ service accessibility}

The term accessibility in this study was applied to geographical accessibility based on adolescents' own perception. Adolescents who lived within 1.6-km (1 mile) radius distance from the nearest $\mathrm{RH}$ service center and from their home less than 30-min walking distance were classified as having high geographical accessibility and low otherwise.

\section{RH service utilization}

Adolescents having sought or received at least one of the four RH services that the study focuses on, that is, $\mathrm{SRH}$ information and education service, modern contraceptive service, VCT service, and STI diagnosis and treatment service utilization.

\section{SRH information and education service utilization}

Adolescents who received information and education regarding sexual and reproductive health issues from health worker working in any of the service providing points within the past 12 months. 


\section{STI diagnosis and treatment service utilization}

Adolescents who ever obtained STI diagnosis and treatment service in their life.

\section{Substance use}

Using addictive substances such as alcohol, 'khat' or cigarette with either frequency of; more repeated than daily, daily, weekly or monthly in the past 12 months prior to the study.

\section{VCT service utilization}

Voluntary Counseling and Testing for HIV is defined as an HIV intervention that includes both voluntary pre and post-test counselling and voluntary HIV testing. In this study, adolescent who ever received HIV counseling and testing service in their life time.

\section{Modern contraceptive}

Modern contraceptive method is defined as a product or medical procedure that interferes with reproduction from acts of sexual intercourse. These methods are; sterilization (male and female), Intrauterine device and systems, subdermal implants, oral contraceptives, condoms (male and female), injectables, emergency contraceptive pills, patches, diaphragms and cervical caps, spermicidal agents in different form, vaginal rings and sponge. In this study, modern contraceptive usage among adolescents was assessed for intrauterine device, oral contraceptives, condoms (male and female), injectables, emergency contraceptive pills and spermicidal agents.

\section{Results}

\section{Socio demographic characteristics of the study} participants

From the total 682 participants, 648 of them responded to the questionnaires yielded a response rate of $95.01 \%$. Out of 648 participants 348 (53.7\%) were males. The mean and median age of the respondents were $17.13(\mathrm{SD}+1.33)$, and 17.0 respectively. Six hundred four (93.2\%) respondents were Orthodox Christian followed by Muslim 27 (4.2\%), and protestant 17 (2.6\%). Based on their ethnic group, Amhara ethnic constituted 611 (94.3\%), and majority of the respondents $624(96.3 \%)$ were single.

Regarding to their school status, 606 (93.5\%) participants were currently enrolled at schools. In contrast, only $5(0.8 \%)$ of the respondents were found without any formal education experience. Among the participants who were attending education, $443(68.4 \%)$ of the respondents reported their educational status as secondary education (Grade 9-12) followed by primary education (Grade 1-8), and above secondary education 132 (20.4\%) and 68 (10.5\%) respectively.

Concerning the Participants' mother educational status, nearly similar figures were reported that lies between 20th and 30th percentile with slight percentage increment in mothers with no formal education 175 (27.0\%). Out of the total respondents, 412 (63.6\%) reported about the absence of discussion habit on sexual and reproductive issues in their family. On the other hand, the median perceived monthly family income was 2095.0 Ethiopian Birr. More than three-fourth, 493 (76.1\%) of the study participants were living with their mother and father together (Table 1).

\section{Respondents' individual attribute related with sexuality and reproductive health}

To assess their knowledge, the study participants were asked about the components of RHS and service delivery points which have a total score of 15 . Accordingly, respondents who had high knowledge (scoring above the mean $=8.6(\mathrm{SD}+3.4))$ were $356(54.9 \%)$. Out of the total participants, $232(35.8 \%)$ have had boy/girlfriends, and among those who had boy/girlfriend, nearly half of them $114(49.1 \%)$ had one boy/girlfriend (mean $=2.06, \mathrm{SD}+$ 1.44). Moreover, one hundred sixty-two $(25.0 \%)$ of the respondents have had sexual intercourse in their life.

One hundred eighty $(27.8 \%)$ of the study participants reported that they have had discussion on at least two of the sexual and reproductive health issues [SRH discussion points; Abstinence, condom use, STI/HIV/AIDS, unwanted pregnancy, contraception] with their peers in the last 12 months prior to the study. Discussion on the same issues was also reported by 88 (13.6\%), and 82 $(12.7 \%)$ of the respondents with their sexual partner and with health workers respectively.

Depending on their risky behavior that leads to being infected with HIV virus, the study participants' perception towards being infected of HIV virus reveals that 559 (86.3\%) respondents perceived themselves as free from HIV infection risks.

Regarding to the participants' last 12-months experience of alcohol, 'khat' or cigarette use: majority of them $568(87.2 \%)$ reported that they didn't consume any of these addictive substances. The remaining use at least one of those drugs at a different regularity. Majority, 28 (33.7\%) of the 'drug-users' who used those drugs less frequent than monthly followed by weekly 20 (24.1\%), monthly 17 (20.5\%), daily $15(18.1 \%)$ and more frequent than daily $3(3.61 \%)$. Considering the operational definition used in this study, 55 (8.5\%) of the respondents had use those substances (Table 2).

\section{Geographical accessibility of reproductive health service delivery points}

Regarding to the accessibility of reproductive health service delivery points, Hospitals and Health centers were among the commonly mentioned service delivery points 250 (38.6\%) and 239 (36.9\%) respectively followed by Clinics (both private and NGOs') 62 (9.6\%). In addition, Pharmacy 
Table 1 Socio-demographic characteristics of adolescents of age 15-19 in Debre Berhan town

\begin{tabular}{|c|c|c|}
\hline Variable & Frequency $n=648$ & Percentage (\%) \\
\hline \multicolumn{3}{|l|}{ Sex } \\
\hline Male & 348 & 53.7 \\
\hline Female & 300 & 46.3 \\
\hline \multicolumn{3}{|l|}{ Age } \\
\hline $15-17$ & 356 & 54.9 \\
\hline $18-19$ & 292 & 45.1 \\
\hline \multicolumn{3}{|l|}{ Ethnicity } \\
\hline Amhara & 611 & 94.3 \\
\hline Oromo & 15 & 2.3 \\
\hline Tigre & 12 & 1.9 \\
\hline Gurage & 9 & 1.4 \\
\hline Other & 1 & 0.15 \\
\hline \multicolumn{3}{|l|}{ Marital status } \\
\hline Single & 624 & 96.3 \\
\hline Married & 19 & 2.9 \\
\hline Divorced & 2 & 0.3 \\
\hline Separated & 3 & 0.5 \\
\hline \multicolumn{3}{|l|}{ Current enrollment at school } \\
\hline In school & 606 & 93.5 \\
\hline Out school & 42 & 6.5 \\
\hline \multicolumn{3}{|l|}{ Educational status } \\
\hline No formal education & 5 & 0.8 \\
\hline Primary education & 132 & 20.4 \\
\hline Secondary education & 443 & 68.4 \\
\hline Above secondary education & 68 & 10.5 \\
\hline \multicolumn{3}{|l|}{ Mother's educational status } \\
\hline No formal education & 175 & 27.0 \\
\hline Primary education & 171 & 26.4 \\
\hline Secondary education & 155 & 23.9 \\
\hline Above secondary education & 147 & 22.7 \\
\hline \multicolumn{3}{|c|}{ Habit of communication within family on SRH issues } \\
\hline Yes & 236 & 36.4 \\
\hline No & 412 & 63.6 \\
\hline \multicolumn{3}{|l|}{ Co-residence with both parents } \\
\hline Yes & 493 & 76.1 \\
\hline No & 155 & 23.9 \\
\hline \multicolumn{3}{|c|}{ Perceived monthly income of the family (ETB) } \\
\hline $150-650$ & 35 & 5.4 \\
\hline $651-1400$ & 134 & 20.7 \\
\hline $1401-2350$ & 167 & 25.8 \\
\hline $2351-3550$ & 139 & 21.5 \\
\hline $3551-5000$ & 104 & 16.0 \\
\hline$>5001$ & 69 & 10.6 \\
\hline
\end{tabular}

Table 2 Adolescents' individual attribute related with sexuality and reproductive health

\begin{tabular}{|c|c|c|c|}
\hline Variable & & $\begin{array}{l}\text { Frequency } \\
n=648\end{array}$ & $\begin{array}{l}\text { Percentage } \\
(\%)\end{array}$ \\
\hline \multirow{2}{*}{$\begin{array}{l}\text { Knowledge about reproductive } \\
\text { health service }\end{array}$} & High & 356 & 54.9 \\
\hline & Low & 292 & 45.1 \\
\hline \multirow[t]{2}{*}{ Ever had sexual intercourse } & Yes & 162 & 25.0 \\
\hline & No & 486 & 75.0 \\
\hline \multirow{2}{*}{$\begin{array}{l}\text { Discuss about SRH issues }{ }^{a} \text { with } \\
\text { sexual partner in the past } \\
12 \text { months }(n=162)\end{array}$} & Yes & 88 & 54.3 \\
\hline & No & 74 & 45.7 \\
\hline \multirow{2}{*}{$\begin{array}{l}\text { Discuss about SRH } \text { issues }^{a} \text { with } \\
\text { peer in the past } 12 \text { months }\end{array}$} & Yes & 180 & 27.8 \\
\hline & No & 468 & 72.2 \\
\hline \multirow{2}{*}{$\begin{array}{l}\text { Discuss about SRH issues }{ }^{a} \text { with } \\
\text { Health worker in the past } 12 \text { months }\end{array}$} & Yes & 82 & 12.7 \\
\hline & No & 566 & 87.3 \\
\hline \multirow[t]{2}{*}{ Perception of risk towards HIV/AIDS } & Yes & 89 & 13.7 \\
\hline & No & 559 & 86.3 \\
\hline \multirow{2}{*}{$\begin{array}{l}\text { Exposure to mass-media on } \\
\text { SRH issues }{ }^{\mathrm{a}} \text { in the past } 12 \text { months }\end{array}$} & Yes & 484 & 74.7 \\
\hline & No & 164 & 25.3 \\
\hline \multirow[t]{2}{*}{ Substance use in the past 6 months } & Yes & 55 & 8.5 \\
\hline & No & 593 & 91.5 \\
\hline
\end{tabular}

a' SRH issues: Abstinence, condom use, STI/HIV/AIDS, unwanted pregnancy, contraception

constitutes $42(6.5 \%)$, Health posts comprise 22 (3.4\%), and Youth friendly health service clubs constitutes 17 (2.6\%), while Health extension workers comprise 16 (2.5\%).

The mean distance from the respondents' home to the nearest service delivery point was $1.43 \mathrm{~km}$ and it was reported to take an average of 19 min to walk. The majority of the participants said that there was $\mathrm{RH}$ service delivery center within a 30-min walk (69.4\%) and within $1.6 \mathrm{~km}$ radius $(88.4 \%)$ from their home which yields an overall high geographical accessibility of $68.5 \%$ and low geographical accessibility of $31.5 \%$. However, there was a slight variation of geographical accessibility between male and female respondents (Table 3).

Table 3 Comparison of geographical accessibility and service utilization between male and female adolescents

\begin{tabular}{|c|c|c|c|c|}
\hline & & \multicolumn{2}{|l|}{ Sex } & \multirow{2}{*}{$\begin{array}{l}\text { Total, n } \\
\text { (\%) }\end{array}$} \\
\hline & & Male (\%) & Female (\%) & \\
\hline \multirow[t]{2}{*}{ Distance from home } & $<1.6 \mathrm{~km}$ & $250(71.8)$ & $200(66.7)$ & $450(69.4)$ \\
\hline & $>1.6 \mathrm{~km}$ & $98(28.2)$ & $100(33.3)$ & 198 (30.6) \\
\hline \multirow[t]{2}{*}{ Walking time } & $\begin{array}{l}\text { Less than } \\
30 \text { min }\end{array}$ & 306 (87.9) & $267(89)$ & $573(88.4)$ \\
\hline & $\begin{array}{l}\text { More than } \\
30 \mathrm{~min}\end{array}$ & $42(12.1)$ & $33(11)$ & 75 (11.6) \\
\hline \multirow{2}{*}{$\begin{array}{l}\text { Overall Geographical } \\
\text { accessibility }\end{array}$} & High & $246(70.7)$ & $198(66.0)$ & $444(68.5)$ \\
\hline & Low & $102(29.3)$ & $102(34.0)$ & $204(31.5)$ \\
\hline
\end{tabular}


Pattern of reproductive health services utilization among adolescents

Nearly, 1 among 3 adolescents, 219 (33.8\%) had used at least one of the reproductive health services (see Fig. 1). Accordingly, among these RH service users $(n=219)$, voluntary counseling and testing service for HIV service accounts 175 (43.6\%) followed by SRH information and education service users 95 (23.7\%), modern contraceptive users 88 (21.9\%), and STI diagnosis and treatment service users 43 (10.7\%) (See Fig. 2).

According to the data obtained on contractive methods used with reference to gender, the most frequently used modern contraceptive method by male adolescents was condom (60.2\%) followed by female adolescents using oral contraceptive pills (20.4\%) (See Fig. 3).

\section{Factors associated with RH service utilization}

Based on the Bivariate analysis, the factors found to be significantly associated with reproductive health service utilization were adolescents age, marital status, and educational status; mothers' educational status; poor family communication habit on SRH issues; co-residence with both parents; family monthly income; history of sexual intercourse; poor discussion on SRH matters with sexual partner, pears, and health workers; perception of risk towards HIV/AIDS; exposure towards mass media; addictive substance or drugs use; and geographical accessibility.

With an intention of controlling confounding effect, variables that were statistically significant with reproductive health service utilization on bivariate analysis were interred in to multiple variable logistic regressions. Based on this analysis, adolescents who had discussed sexual and reproductive health issues with their sexual partner and peers were two times more likely to use at least one of the four $\mathrm{RH}$ services than their counter parts $(\mathrm{AOR}=2.368$, 95\% CI: $1.168-4.802$ and $\mathrm{AOR}=2.360$, 95\% CI: $1.155-$ 4.820 respectively). Adolescents who weren't co-resided with both their parents were about two times more likely to utilize RH service than those who were living together
(AOR $=2.570,95 \% \mathrm{CI}=1.155-4.820)$. Positive perception of oneself towards being infected of HIV/AIDS was a driven force for the adolescents to use $\mathrm{RH}$ services twice than those who didn't perceive themselves as risky (AOR $=2.231,95 \%$ CI: 1.001-4.975) (Table 4).

\section{Discussion}

This study revealed that the overall service utilization was $33.8 \%$ which is much smaller than study conducted in Mandalay city, Myanmar (67\%), and Gondar town, Ethiopia $(79.5 \%)[11,12]$. This variation was possibly due to economical, and socio demographical variations, for example, the study in Myanmar was conducted in the age group of 15-24, and maternal care also included in the service package which may inflate the figure in Mandalay city. In contrast, the study done in Gondar town specifically focused on those adolescents who had sexual exposure which potentially increase the likelihood of service usage. However, adolescents' service utilization in this study was slightly closer to similar study conducted in Jimma town, Ethiopia which is $41.1 \%$ [13].

Succinctly speaking, Twenty-three percent of the participants in this study utilize information and education related with sexual and reproductive health from health care workers, and this finding has concordance with the study done in Jimma town which is $28.8 \%$. With regard to modern contraception utilization, the record in this study which was $21.9 \%$ reveals similarity with the results of large scale survey done in 35 countries in Africa on contraceptive methods usage among adolescents of age 15-19 [14]. Family planning service usage in rural areas of East Gojjam and in Jimma town were also 27.7 and $16.3 \%$ respectively $[13,15]$ which didn't show a great deal of variation with this study findings.

This study revealed that voluntary counseling and testing service utilization for HIV is $43.6 \%$, which has remarkable variation with research findings in Gondar and Goba town 72.2 and $67.3 \%$ respectively. This variation could be due to adolescents' perception of the risk

\section{- Users $\quad$ Non-users}

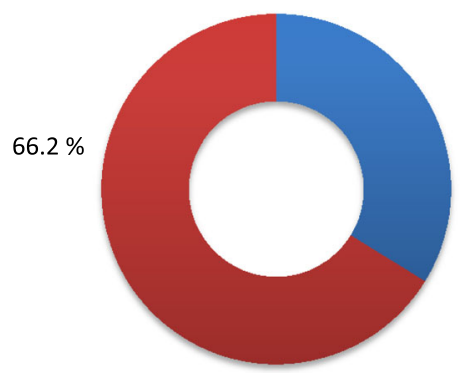

$33.8 \%$

Fig. 1 Magnitude of reproductive health services utilization among adolescents 


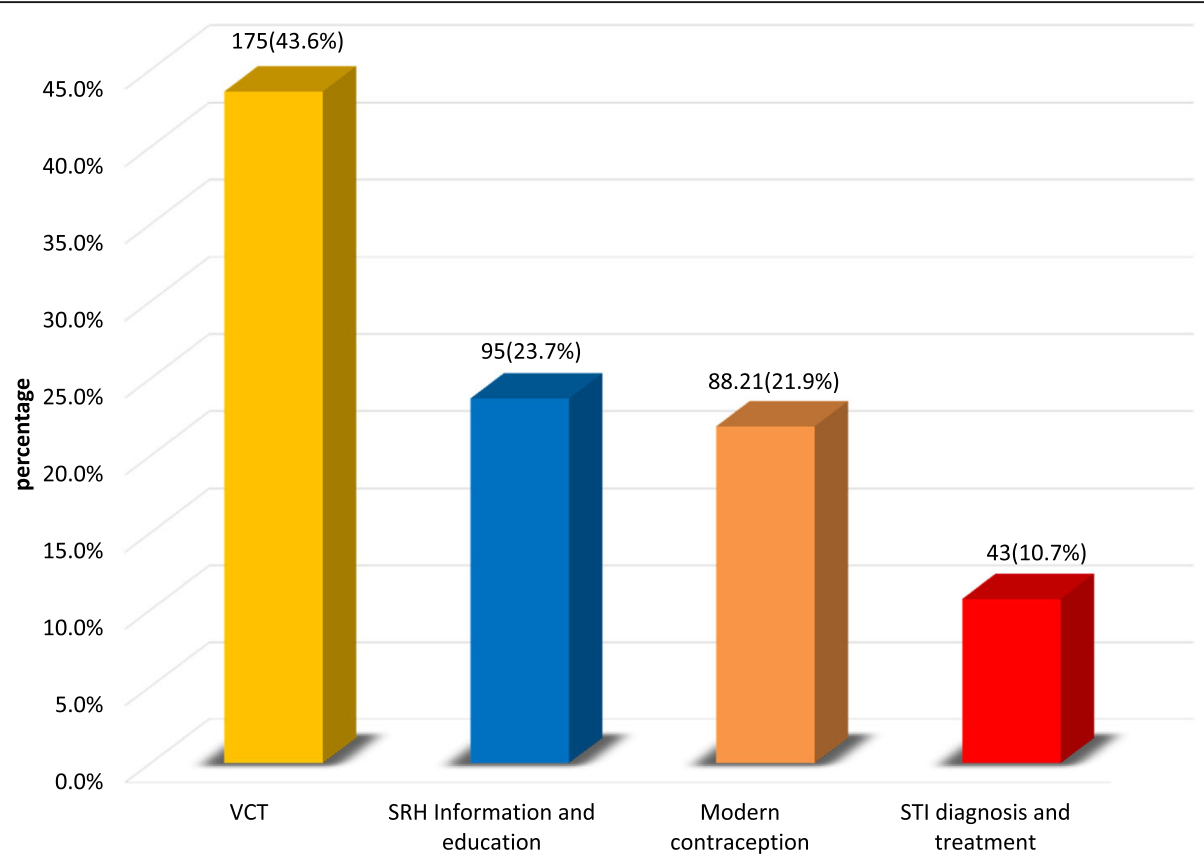

Fig. 2 Type of reproductive Health services utilized by adolescents

towards HIV virus which was lesser in this study and the recent nationwide noticeable emphasis decrement on the fight against HIV virus related health promotion and prevention activities.

Communication of sexual and reproductive health issues within the family (especially if the family members have good knowledge on reproductive health problems and reproductive health services) allows the adolescent to enhance their knowledge, build their confidence and in turn scale up their tendency to use those services in demand. Unfortunately, $63.6 \%$ of the study participants in this study reported that the absence of communication habit on sexual and reproductive health matters within their family. Nearly similar record was obtained from research conducted in East Gojjam area $(68.0 \%)$ and Goba town $(54.2 \%)[15,16]$.
It is obvious that measuring service accessibility needs multiple considerations, but to utilize the services, adolescents' level of knowledge has an indispensable role. Advocating and increasing awareness about SRH is also central for the success of any adolescent reproductive health program. Knowing which type of service provider can provide the different kinds of services enables adolescents to use services effectively as they needed them. In this study, about $55 \%$ of the adolescents had high level of knowledge on RH services and providers compared to $67 \%$ in East Gojjam research findings. This could be due to the difference in knowledge assessing tool. The mean score of knowledge assessing questions in this study (mean $=8.6(\mathrm{SD}+3.4))$ exceed two times more than a study that used the same knowledge assessing tool in Mandalay city, Myanmar (mean = $3.3(\mathrm{SD}+1.6))$ [11].

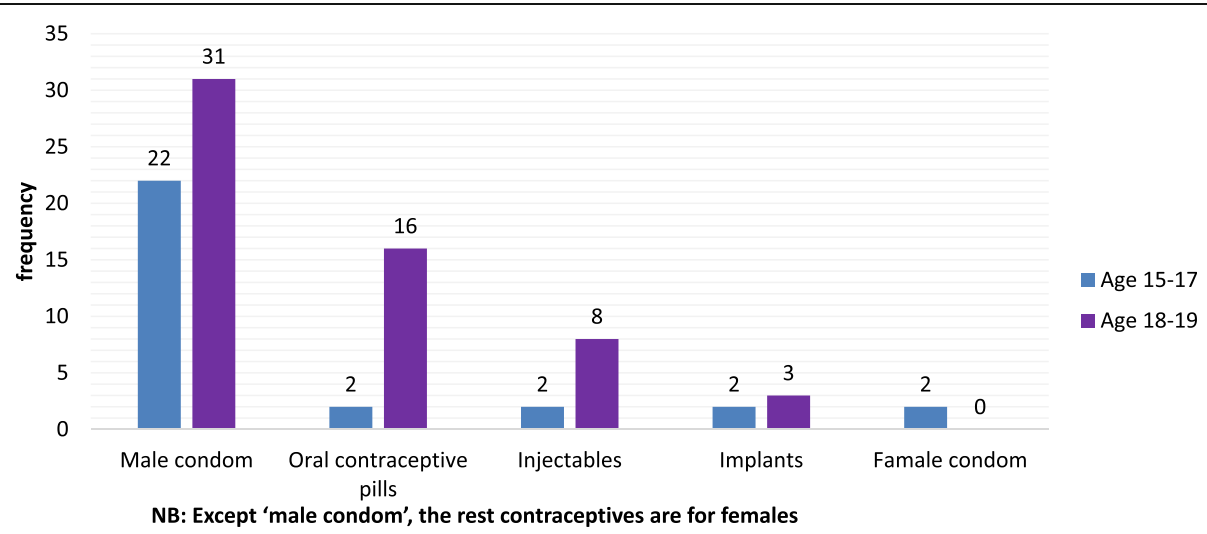

Fig. 3 A comparison of modern contraception types used with the age category of adolescents 
Table 4 Multiple variable logistic regression of factors associated with utilization of RH service

\begin{tabular}{|c|c|c|c|c|}
\hline \multirow[t]{2}{*}{ Variables } & \multicolumn{2}{|c|}{ RHS utilization } & \multirow[t]{2}{*}{ COR } & \multirow[t]{2}{*}{$\mathrm{AOR}$} \\
\hline & YES & $\mathrm{NO}$ & & \\
\hline \multicolumn{5}{|l|}{ Age } \\
\hline $15-17$ & 96 & 260 & 1 & 1 \\
\hline $18-19$ & 123 & 169 & $1.97(1.42-2.74)$ & $1.214(0.56-2.62)$ \\
\hline \multicolumn{5}{|l|}{ Educational status } \\
\hline No formal education & 2 & 3 & $1.36(0.22-8.21)$ & $1.20(0.82-6.22)$ \\
\hline Primary education (1-8) & 39 & 93 & $0.85(0.56-1.30)$ & $1.00(0.34-2.95)$ \\
\hline Above secondary education & 32 & 36 & $1.81(1.08-3.03)$ & $1.20(0.36-3.99)$ \\
\hline Secondary education (9-12) & 146 & 297 & 1 & 1 \\
\hline \multicolumn{5}{|l|}{ Mother's educational status } \\
\hline No formal education & 66 & 109 & 1 & 1 \\
\hline Primary education (1-8) & 73 & 98 & $1.23(0.80-1.89)$ & $0.68(0.23-2.05)$ \\
\hline Secondary education (9-12) & 42 & 113 & $0.61(0.38-0.98)$ & $0.68(0.21-2.15)$ \\
\hline Above secondary education & 38 & 109 & $0.58(0.36-0.93)$ & $1.13(0.29-4.39)$ \\
\hline \multicolumn{5}{|c|}{ Habit of communication with in family on SRH issues } \\
\hline Yes & 106 & 130 & $2.16(1.54-3.02)$ & $1.66(0.81-3.40)$ \\
\hline No & 113 & 299 & 1 & 1 \\
\hline \multicolumn{5}{|l|}{ Co-residence with both parents } \\
\hline Yes & 148 & 345 & 1 & 1 \\
\hline No & 71 & 84 & $1.97(1.36-2.85)$ & $2.57(1.07-6.17)^{\mathrm{a}}$ \\
\hline \multicolumn{5}{|l|}{ Ever had sexual intercourse } \\
\hline Yes & 112 & 50 & $7.93(5.34-11.79)$ & $2.02(0.89-6.78)$ \\
\hline No & 107 & 379 & 1 & 1 \\
\hline \multicolumn{5}{|l|}{ Perceived monthly family income } \\
\hline $1401-2350$ & 56 & 111 & 1 & 1 \\
\hline $150-650$ & 18 & 17 & $2.20(1.01-4.38)$ & $1.80(0.25-12.80)$ \\
\hline $651-1400$ & 57 & 77 & $1.47(0.91-2.35)$ & $2.06(0.71-5.96)$ \\
\hline $2351-3550$ & 33 & 106 & $0.62(0.37-1.02)$ & $1.19(0.39-3.69)$ \\
\hline $3551-5000$ & 32 & 72 & $0.881(0.52-1.49)$ & $1.48(0.45-4.86)$ \\
\hline$>5000$ & 23 & 46 & $0.991(0.55-1.80)$ & $3.04(0.62-14.98)$ \\
\hline \multicolumn{5}{|c|}{ Discussion with sexual partner $(n=162)$} \\
\hline Yes & 68 & 20 & $2.32(1.17-4.58)$ & $2.37(1.17-4.80)^{\mathrm{a}}$ \\
\hline No & 44 & 30 & 1 & 1 \\
\hline \multicolumn{5}{|l|}{ Discussion with peers } \\
\hline Yes & 94 & 86 & $2.99(2.01-4.28)$ & $2.36(1.16-4.82)^{\mathrm{a}}$ \\
\hline No & 125 & 343 & 1 & 1 \\
\hline \multicolumn{5}{|l|}{ Discussion with health workers } \\
\hline Yes & 47 & 35 & $3.08(1.92-4.94)$ & $2.89(0.03-8.03)$ \\
\hline No & 172 & 394 & 1 & 1 \\
\hline \multicolumn{5}{|c|}{ Perception of risk towards HIV/AIDS } \\
\hline Yes & 53 & 36 & $3.49(2.20-5.52)$ & $2.23(1.00-4.98)^{\mathrm{a}}$ \\
\hline No & 166 & 393 & 1 & 1 \\
\hline
\end{tabular}


Table 4 Multiple variable logistic regression of factors associated with utilization of RH service (Continued)

\begin{tabular}{|c|c|c|c|c|}
\hline \multirow[t]{2}{*}{ Variables } & \multicolumn{2}{|c|}{ RHS utilization } & \multirow[t]{2}{*}{ COR } & \multirow[t]{2}{*}{ AOR } \\
\hline & YES & $\mathrm{NO}$ & & \\
\hline \multicolumn{5}{|c|}{ Exposure to mass-media } \\
\hline Yes & 183 & 301 & $2.16(1.43-3.27)$ & $0.80(0.27-2.38)$ \\
\hline No & 36 & 128 & 1 & 1 \\
\hline \multicolumn{5}{|c|}{ Substance use } \\
\hline Yes & 33 & 22 & $3.28(1.86-5.79)$ & $1.90(0.73-4.98)$ \\
\hline No & 186 & 407 & 1 & 1 \\
\hline \multicolumn{5}{|c|}{ Geographical accessibility } \\
\hline High & 136 & 308 & $0.64(0.46-0.91)$ & $1.04(0.45-2.40)$ \\
\hline Low & 83 & 121 & 1 & 1 \\
\hline
\end{tabular}

${ }^{a}$ statistically significant association

In this study, the researcher found that family factors played an important role in youths' utilization of RH services. For instance, adolescents who weren't co-resided with both their parents were 2.57 times more likely to use $\mathrm{RH}$ services than those who live together with their parents. This finding is against the study in Gondar town where adolescents living with both of their parents together use VCT service more likely than their counter parts. This could be due to relatively high parental monitoring in our setting. In addition to this, even though majority of the respondents in this study were living with both their parents, the families' habit of communication on sexual and reproductive issues were quite low (36.2\%).

Adolescents' high-risk perception towards HIV/AIDS drives them to seek and utilize RH service more likely than those who didn't perceive it. This finding was similar to other studies conducted in Madawalabu University and Gondar town $[12,17]$. The above two studies mentioned and other research findings revealed that discussion on sexual and reproductive health matters with sexual partner and peers increase the chance of service utilization $[13,16]$. Similarly, this study revealed that adolescents who had discussions on SRH issues with their sexual partners and peers were found to be two times more likely to use SRH services than those who didn't have the opportunity to discuss the matter.

\section{Conclusion and recommendations}

The findings of this study suggest that RH services among adolescents in the study area were low (33.8\%). Voluntary counseling and testing for HIV was the most frequently used service and on the contrary, STI diagnosis and treatment was the low. Co-residence with both parents, discussion with sexual partner and peers, risk perception of oneself towards being infected with HIV/AIDS was among the factors associated with use of $\mathrm{RH}$ services.
Therefore, considering the bio-physical and psychological changes of adolescents' the discussion on sexual and reproductive health matters is highly important and expected from every family. Since majority of adolescents at this age invest most of their time at school, schools can be an excellent means to advance adolescents' knowledge, attitude and exposure towards $\mathrm{RH}$ services. Hence, the school's administration should endeavor to create conducive environment that helps the adolescents to discuss on their issues and experiences related to RH services. The Regional Health Bureau and North Shoa Zone Health office still needs to reform the existing practice, and establish new comprehensive free standing or integrated adolescent friendly-services with trained service provider in a convenient manner because attempting to achieve prolific outcome require considering adolescents' need which is dynamic, confidential and flexible by its nature.

\section{Additional file}

Additional file 1: Questionnaire to assess reproductive health service utilization and its associated factors among adolescents in Debre Berhan Town, Central Ethiopia. (PDF 212 kb)

\section{Abbreviations}

EDHS: Ethiopian Demographic and Health Survey; ICPD: International Conference on Population Development; IRB: Institutional Review Board; Kebele*: The smallest administrative structural unit of the town (*local name); $\mathrm{RH}$ : Reproductive Health; RHS: Reproductive Health Service; STD: Sexually Transmitted Disease; VCT: Voluntary Counseling and Testing (for HIV); WHO: World Health Organization

\section{Acknowledgements}

The authors would like to thank Addis Ababa University for financial support. Moreover, the authors would like to extend their sincere gratitude for all study participants, supervisors and data collectors for their unreserved efforts and willingness to take part in this study. Last but not the least, the authors would like to thank Mr. Zenebe Hailu for his extensive effort to advance the English language commands we used in this paper.

Funding

This study was funded by Addis Ababa University, Ethiopia. 


\section{Availability of data and materials}

The data sets used for analysis during the current study are available from the corresponding author on reasonable request.

\section{Authors' contributions}

KG was involved in the conception, design, analysis, interpretation, report and manuscript writing; MA, TM and MA were participated in reviewing both the proposal and the final report. FH was involved in designing the study, analysis, interpretation, report and manuscript writing. All authors have read and approved the final manuscript.

\section{Ethics approval and consent to participate}

Ethical clearance was obtained from Addis Ababa University College of Health Science, Department of Nursing and Midwifery Institutional review board (IRB). Official letter was received from the department of Nursing and Midwifery and submitted to North Shoa Zone Health Office. The office permitted the request and announces each selected kebeles' administration office for cooperation. The purpose of the study was explained to participants. Informed consent was obtained from participants more than 18 years old and oral consent was obtained from parents under the age of 18. Confidentiality was reserved. Participants' involvement in the study was on voluntary basis and they didn't ask to write neither their name nor their address.

\section{Competing interests}

The authors declare that they have no competing interest.

\section{Publisher's Note}

Springer Nature remains neutral with regard to jurisdictional claims in published maps and institutional affiliations.

\section{Author details}

'Nursing Department, Health Science Faculty, Woldia University, Woldia, Ethiopia. ${ }^{2}$ School of Nursing and Midwifery, College of Health Science, Addis Ababa University, Addis Ababa, Ethiopia. ${ }^{3}$ School of Public Health, College of Health Sciences and Medicine, Hawassa University, Hawassa, Ethiopia.

Received: 25 October 2018 Accepted: 10 December 2018 Published online: 27 December 2018

\section{References}

1. WHO: Programming for adolescent health and development report of World Health Organization/ United Nations population fund / the United Nations international Children's emergency fund study group on programming for adolescent's health. Geneva: WHO; 2009.

2. WHO and Deutsche Gesellschaft fuerTechnischeZusammenarbeit GmbH. Sexually transmitted infections among adolescents: the need for adequate health services. Geneva: World Health Organization Library Cataloguing-inPublication Data; 2010

3. Roudi-Fahimi F, Ashford L. Sexual and reproductive health in the Middle East and North Africa: a guide for reporters. Washington DC: Population Reference Bureau; 2008.

4. US Population Council. Poverty, gender and youth: premarital sex and schooling transitions in four sub-Saharan African countries 2011. In: New York; 2012.

5. Central Statistical Agency [Ethiopia] and ICF International. Ethiopia Demographic and Health Survey 2011. Addis Ababa, Ethiopia and Calverton, Maryland, USA: Central Statistical Agency and ICF International; 2012.

6. Shivaram K, Nandini C, Malleshappal K. Knowledge and attitude about reproductive health among rural adolescent girls in Kuppammandal: an intervention study. Biomed Res. 2011;22(3):305-10.

7. Hughes J, McCauley AP. Improving the fit: adolescents' needs and future programs for sexual and reproductive health in developing countries studies in family planning. Stud Fam Plan. 2008;29(2):233-45.

8. FHI/Youth Net. Assessment of youth reproductive health programs in Ethiopia. Addis Ababa, Ethiopia: Family Health International; 2008.

9. Braeken D, Rondinelli I. Sexual and reproductive health needs of young people: matching needs with systems. Int J Gynecol Obstet. 2012;119:S60-3.

10. John Cleland. Illustrative questionnaire for interview-survey with young peoples. Part II. Available at: https://www.who.int/reproductivehealth/topics/ adolescence/questionnaire.pdf. [Accessed Jan 2016].
11. Phyu P, Zaw T, Liabsuetrakul T, Htay TT, Mcneil E. Equity of access to reproductive health services among youths in resource-limited suburban communities of Mandalay City. Myanmar BMC Health Serv Res. 2011; 12(1472-6963):1-12.

12. Senafikish Amsalu Feleke and DigsuNegeseKoye, Amsalu FelekeDemssie and Zelalem BirhanuMengesha. Reproductive health service utilization and associated factors among adolescents (15-19 years old) in Gondar town, Northwest Ethiopia.2012. ;13(1):294.

13. Ayalew T, Tegegn A, Gelaw Y. Adolesce t reproductive health services in Jimma city : accessibility and utilization. Ethiop J Heal Sci. 2004;19(2, 4):91-102.

14. Woog V, Singh S, Browne A, Philbin J, Woog V, Singh S, et al. Adolescent women's need for and use of sexual and reproductive health Services in Developing Countries. 2014

15. Abajobir AA, Seme A. Reproductive health knowledge and services utilization among rural adolescents in east Gojjam zone, Ethiopia : a community-based cross-sectional study. BMC Health Serv Res. 2012;14(1):1-11.

16. Gebreselassie B, Takele A, Bililign N, Adera A. Yonas Yimam Ayene AW. Assessment of reproductive health service utilization and associated factors among adolescents ( $15-19$ years old ) in Goba town, Southeast Ethiopia. Am J Heal Res. 2014;3(4):203-12.

17. Dida Nagasa, Birhanu Darega and Abulie Takele. Reproductive health services utilization and its associated factors among Madawalabu University students, Southeast Ethiopia: cross-sectional study 2014; 1-8.

\section{Ready to submit your research? Choose BMC and benefit from:}

- fast, convenient online submission

- thorough peer review by experienced researchers in your field

- rapid publication on acceptance

- support for research data, including large and complex data types

- gold Open Access which fosters wider collaboration and increased citations

- maximum visibility for your research: over $100 \mathrm{M}$ website views per year

At $\mathrm{BMC}$, research is always in progress.

Learn more biomedcentral.com/submissions 